\title{
Molybdenum isotope constraints on the temporal development of sulfidic conditions during Mediterranean sapropel intervals
}

\author{
T. Sweere ${ }^{1,2^{*}}$, R. Hennekam ${ }^{1,2}$, D. Vance ${ }^{2}$, G.-J. Reichart ${ }^{1,3}$
}

Abstract

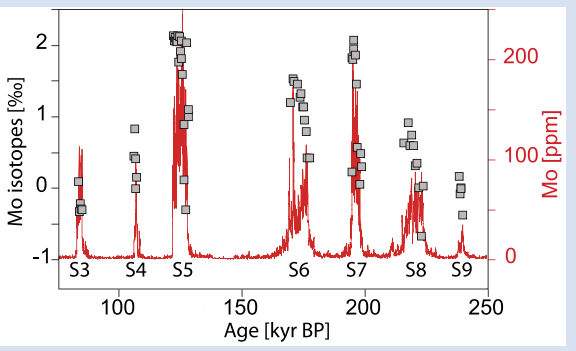

Mediterranean sapropels represent some of the largest scale deoxygenation events in recent Earth history. Here, we use high resolution Mo isotope data for seven such events (sapropels S3 to S9) to semi-quantitatively constrain past $\mathrm{H}_{2} \mathrm{~S}$ concentrations using a new interpretive framework. Bottom water $\mathrm{H}_{2} \mathrm{~S}$ was present for all studied sapropels, but the extent of redox changes varied considerably between them, the ultimate driver likely being variations in monsoon strength. Nearquantitative removal of Mo $\left(\delta^{98} \mathrm{Mo}>2 \%\right.$ ) during deposition of sapropels S5 and S7 suggests predominantly highly sulfidic conditions with long deep water residence times, comparable to the modern Black Sea, whereas considerably lower $\delta^{98}$ Mo values for sapropels S3, S4, S8, and S9 ( -0.4 to $+0.9 \%$ imply mildly euxinic conditions only $\left(0<\mathrm{H}_{2} \mathrm{~S}<11 \mu \mathrm{mol} / \mathrm{L}\right)$. The high resolution data reveal consistent temporal patterns that track the development of basin restriction and euxinia over several kyr. These observations illustrate how Mo isotopes can provide quantitative constraints on basin wide redox changes on relatively short time scales.

Received 13 October 2020 | Accepted 22 January 2021 | Published 18 February 2021

\section{Introduction}

Reconstructions of past deoxygenation events from the sedimentary record are crucial in improving projections of future deoxygenation and associated perturbations to biogeochemical cycles. Organic-rich sapropel layers in the Mediterranean reflect some of the largest scale basin deoxygenation events in recent Earth history. The setting allows the study of repeated intervals of basin deoxygenation of various intensities, at high resolution and within a well established stratigraphic framework.

The timing of Mediterranean sapropel deposition is controlled by maxima in Northern hemisphere summer insolation during precession minima, which lead to higher monsoon intensity over the North African continent (e.g., Ziegler et al., 2010; Grant et al., 2016). Greater freshwater input resulted in nutrient-rich conditions, enhanced water column stratification, and a decrease in local deep water formation, which ultimately caused the drawdown of dissolved oxygen at depth and the deposition of sapropels (e.g., Rohling et al., 2015). As the environmental boundary conditions during these events are relatively well established, sapropels present excellent analogues for intermittent anoxic and sulfidic conditions in past ocean basins (e.g., Dahl et al., 2019) as well as targets for modelling efforts aiming to address large scale basin deoxygenation, provided that redox conditions are quantitatively constrained.

Molybdenum (Mo) concentrations of marine sediments are well established as a tracer for local marine redox conditions, while its isotopes have more recently emerged as a valuable proxy to estimate redox conditions on local to global spatial scales (e.g., Scott and Lyons, 2012; Kendall et al., 2017 and references therein). In oxic waters, dissolved Mo is mostly present as the molybdate ion $\left(\mathrm{MoO}_{4}^{2-}\right)$, which behaves conservatively. However, in the presence of $\mathrm{H}_{2} \mathrm{~S}$, conversion of molybdate to particle-reactive thiomolybdate species $\left(\mathrm{MoO}_{4-x} \mathrm{~S}_{\mathrm{x}}^{2-}\right)$ results in the enhanced export and burial of Mo (Erickson and Helz, 2000). High sedimentary Mo enrichments can thus be taken to reflect sulfidic water column conditions (e.g., Scott and Lyons, 2012).

The Mo isotope composition of organic-rich sediments is generally lighter than seawater (2.34\%o; Nakagawa et al., 2012), with reported $\delta^{98} \mathrm{Mo}$ values as low as $\sim-0.7 \%$ o (e.g., Andersen et al., 2020; Brüske et al., 2020). Low $\delta^{98}$ Mo values in mildly euxinic environments can be attributed to isotope fractionation associated with the incomplete conversion of molybdate to thiomolybdate species, with the more sulfidised species becoming progressively isotopically lighter (Tossell, 2005; Kerl et al., 2017). Large isotopic differences between sediments and seawater for such sediments can be modelled by the kinetically controlled preferential scavenging of the more sulfidised thiomolybdate species (Dahl et al., 2010; Matthews et al., 2017). Sedimentary Mo isotope values only approach the original seawater composition in strongly restricted and euxinic basins (e.g., Neubert et al., 2008; Brüske et al., 2020). Mo isotope data have been published previously only for sapropels S1 and S5 and show highly contrasting values. High $\delta^{98} \mathrm{Mo}$ (up to $\sim 2.3 \%$ ) values have been found for S5, reflecting strongly euxinic conditions with long deep water renewal times (Andersen et al., 2018). By contrast,

\footnotetext{
1. NIOZ Royal Netherlands Institute for Sea Research and Utrecht University, Texel, The Netherlands

. Institute of Geochemistry and Petrology, Department of Earth Sciences, ETH Zürich, Zürich, Switzerland

Department of Earth Sciences, Utrecht University, Utrecht, The Netherlands

Corresponding author (email: tim.sweere@erdw.ethz.ch)
} 


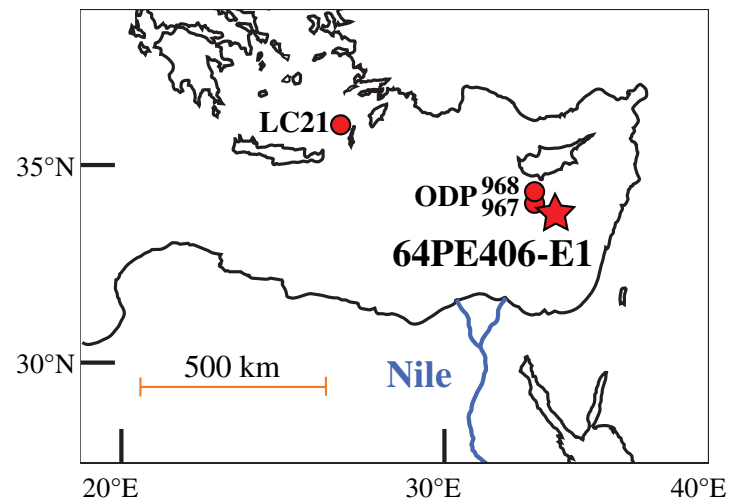

Figure 1 Location of piston core 64PE406-E1 (this study), the LC21, and ODP 968 cores used for the age model, and ODP 967 studied by Andersen et al. (2018).

low $\delta^{98}$ Mo values (mostly $<1 \%$ ) have been found for sapropel $\mathrm{S} 1$, indicating on average lower bottom water $\mathrm{H}_{2} \mathrm{~S}$ concentrations (Reitz et al., 2007; Azrieli-Tal et al., 2014; Matthews et al., 2017; Andersen et al., 2020).

The Eastern Mediterranean is punctuated by at least 6 further deoxygenation events during the last $\sim 300 \mathrm{kyr}$, but basin redox conditions have not been quantitatively constrained for these periods. Here, we provide semi-quantitative constraints on bottom water $\mathrm{H}_{2} \mathrm{~S}$ concentrations for these recent short lived $\left(<10^{4}\right.$ years) deoxygenation events in the Eastern Mediterranean Sea during deposition of sapropels S3 to S9, that reveal a range of different redox conditions (see Supplementary Information for a description of the methodology and results). High resolution Mo concentration (mm scale) and isotope ( $\mathrm{cm}$ scale) data allow a detailed assessment of the temporal evolution of the dissolved Mo pool on kyr time scales, which is used to reconstruct the development of deep water redox conditions and residence times.

\section{Discussion}

Inter-Sapropel Comparisons. Low $\delta^{98} \mathrm{Mo}$ values and Mo concentrations for sapropels S3, S4, and S9 of core 64PE406-E1
(Fig. 1; Supplementary Information) are similar to those previously published values for sapropel S1, suggesting that these sediments were deposited under mildly euxinic conditions $\left(\left[\mathrm{H}_{2} \mathrm{~S}\right]<11 \mu \mathrm{M}\right)$ (Fig. 2; Azrieli-Tall et al., 2014; Matthews et al., 2017; Andersen et al., 2020). Alternative models for low $\delta^{98} \mathrm{Mo}$ values for these sediments, such as deposition associated with Fe or Mn (oxyhydr)oxides (e.g., Reitz et al., 2007) are not supported by the $\mathrm{Mn}, \mathrm{Mo}$, and $\mathrm{U}$ concentration data as these data do not show evidence for a strong Fe-Mn particulate shuttle (Supplementary Information; Figs. S-3 to S-5). High $\delta^{98} \mathrm{Mo}$ values and Mo concentrations for S5 and S7 can mostly be explained by smaller fractionations and more complete removal from seawater in more euxinic conditions. These same intervals are thought to have experienced the highest monsoon intensity over the North African continent in the last $300 \mathrm{kyr}$, suggesting a direct link between monsoon strength and degree of basin deoxygenation (Fig. 2; Ziegler et al., 2010; Grant et al., 2016).

Interpretative Framework for Mo Concentrations and Isotopes. Combining Black Sea surface sediment data and a mechanistic understanding of Mo isotope systematics derived from kinetic models (Matthews et al., 2017) may facilitate a more detailed interpretation of sedimentary Mo signals. Surface sediment data from different Black Sea water depths highlights systematic patterns that reflect variations in dissolved $\mathrm{Mo}$ and $\mathrm{H}_{2} \mathrm{~S}$ concentrations (Fig. 3a). A generally good agreement between Black Sea sediment data and models based on higher particle affinities for the more sulfidised thiomolybdate species (Matthews et al., 2017) implies that $\delta^{98} \mathrm{Mo}$ values may be used to constrain past bottom water $\mathrm{H}_{2} \mathrm{~S}$ concentrations (Fig. 3b). This relationship between sedimentary $\delta^{98} \mathrm{Mo}$ values and $\left[\mathrm{H}_{2} \mathrm{~S}\right]$ depends on (1) Mo speciation as a function of $\mathrm{H}_{2} \mathrm{~S}$, (2) fractionation factors between the different Mo species, (3) the isotopic composition of seawater, and (4) particle affinities of the different thiomolybdate species. Currently, the largest uncertainty in this approach is associated with particle affinities because these are not constrained by direct measurements. Particle affinities for different thiomolybdate species can be described by partition coefficients, i.e. $\mathrm{K}_{i}=\left[\mathrm{MoO}_{4-i} \mathrm{~S}_{i}^{2-}\right]_{\text {particulate }} /\left[\mathrm{MoO}_{4-i} \mathrm{~S}_{i}^{2-}\right]_{\text {dissolved, with } i \text { being }}$ the number of S atoms (Dahl et al., 2010). Previously, much higher particle affinities for the more sulfidised species have been proposed $\left(K_{0}, K_{1}, K_{2}, K_{3}, K_{4}=0,0,1,25,100\right)$ but these

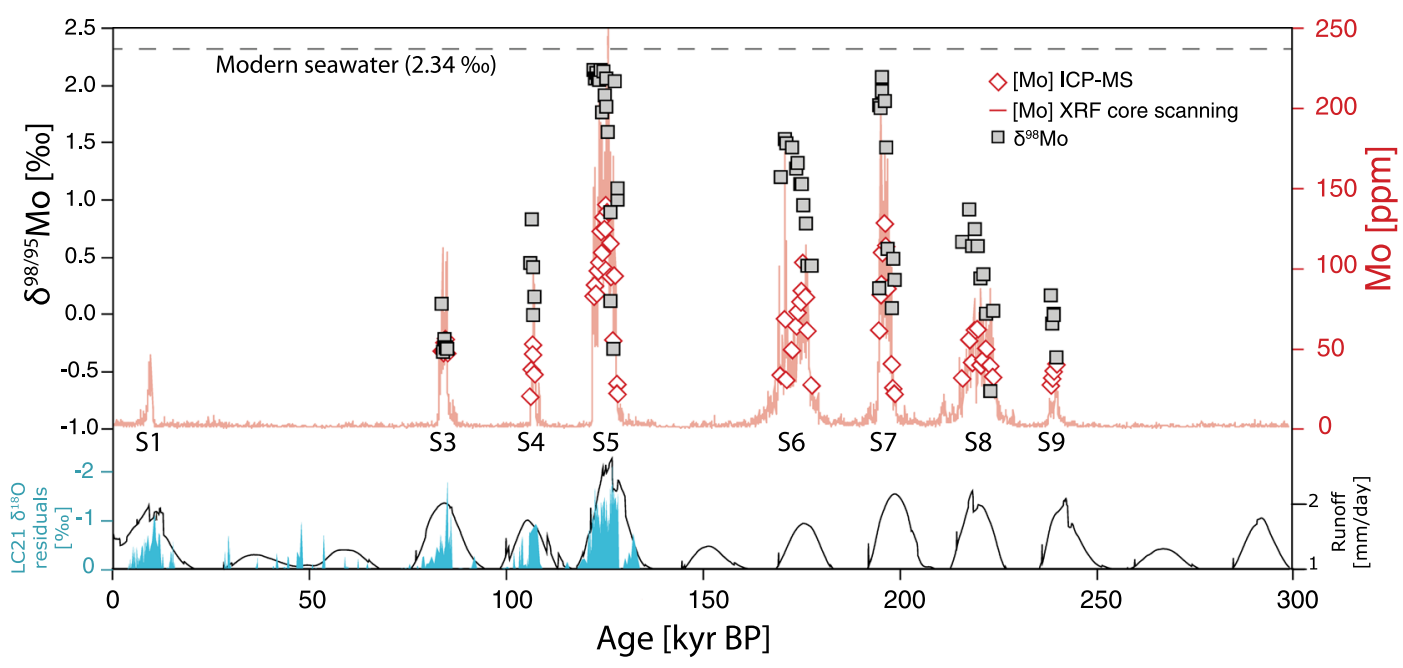

Figure $2 \delta^{98} \mathrm{Mo}$ and Mo concentration data for core 64PE406-E1. The bottom panel reflects indicators of monsoon-driven freshwater input. LC21 core 'residuals' (blue) show the $\delta^{18} \mathrm{O}_{\text {G. ruber }}$ values up to $150 \mathrm{ka}$ BP after correction for a seawater effect (Grant et al., 2016). The black line shows the modelled North African run off (CLIMBER-2; Ziegler et al., 2010). XRF core scanning data by Hennekam et al. (2020). The uncertainties ( 2 s.d.) on the Mo isotope data are smaller than the symbol sizes. 

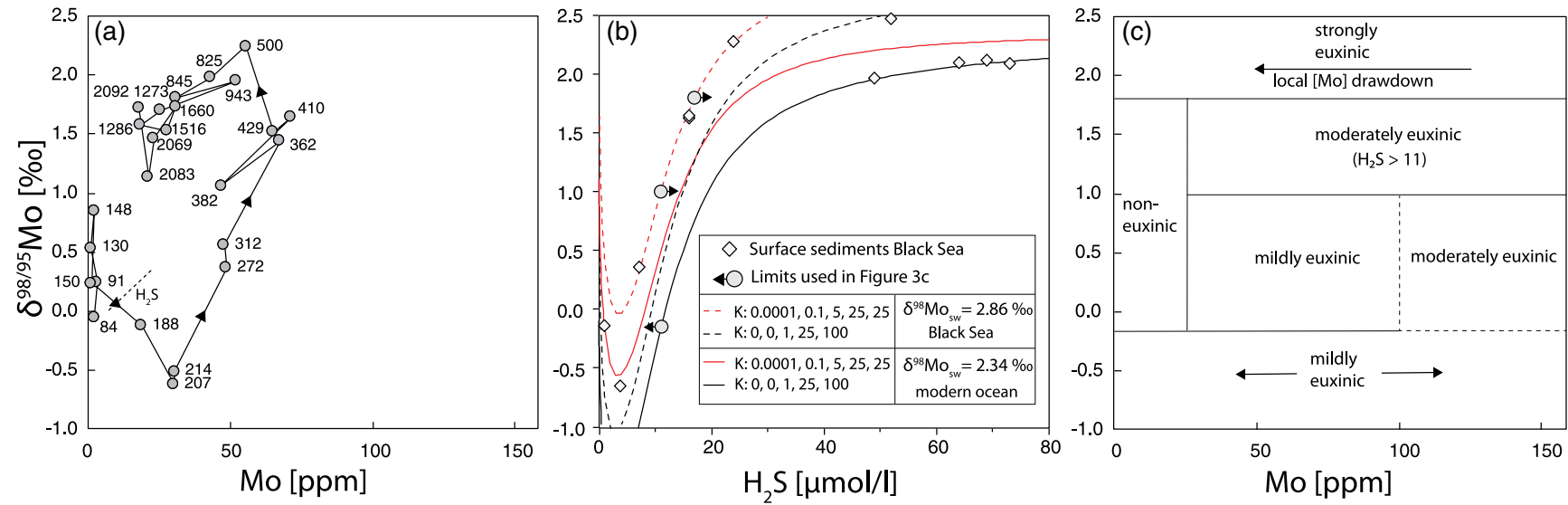

Figure 3 Mo isotope systematics. (a) Surface sediment (0-1 cm depth) data from different water depths (as data labels) in the modern Black Sea (Neubert et al., 2008; Brüske et al., 2020). (b) Sedimentary $\delta^{98}$ Mo values as a function of aqueous $\mathrm{H}_{2} \mathrm{~S}$ concentrations following calculations by Matthews et al. (2017) for different relative particle affinities and seawater $\delta^{98} \mathrm{Mo}$. The $2.86 \%$ value is the average of deep Black

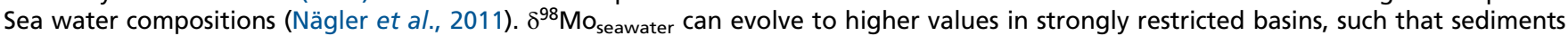
formed from an evolved water mass might show higher $\delta^{98}$ Mo values. The grey circles represent constraints on $\left[\mathrm{H}_{2} \mathrm{~S}\right]$ from $\delta^{98} \mathrm{Mo}$ that agree with all four models and are therefore used in Figure $3 c$ to constrain $\left[\mathrm{H}_{2} \mathrm{~S}\right]$ conservatively. Sediment data from Neubert et al. (2008). (c) Framework for the semi-quantitative reconstruction of $\left[\mathrm{H}_{2} \mathrm{~S}\right]$

s9
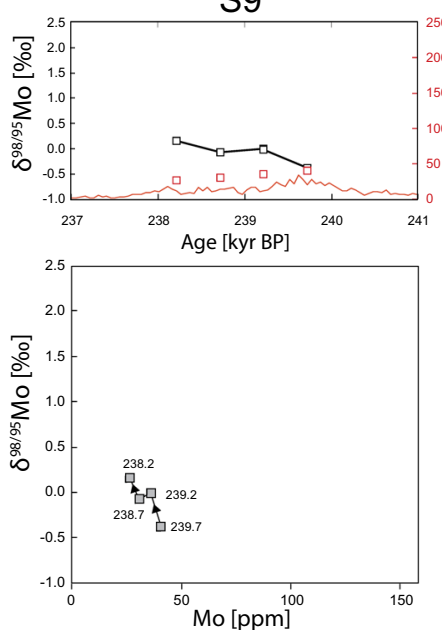

S6
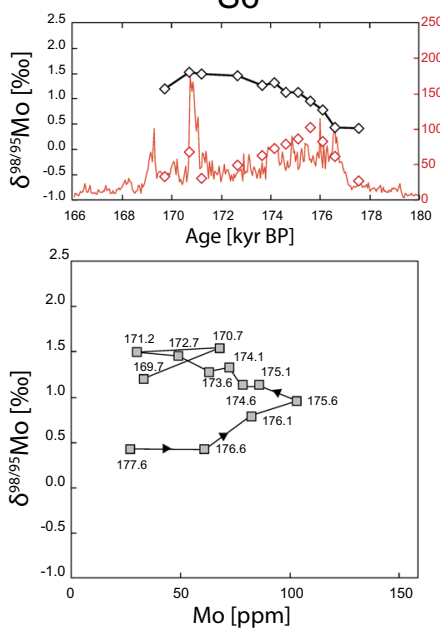

S3
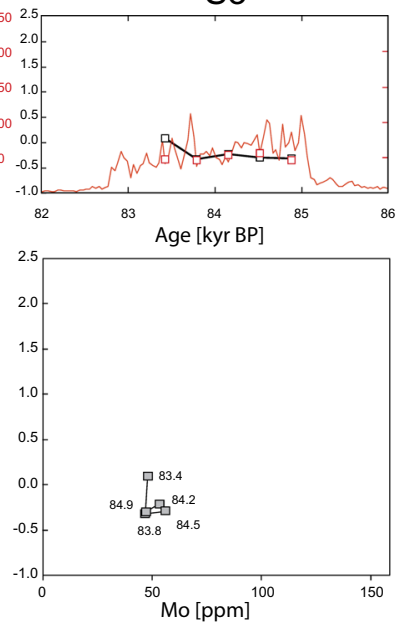

S7
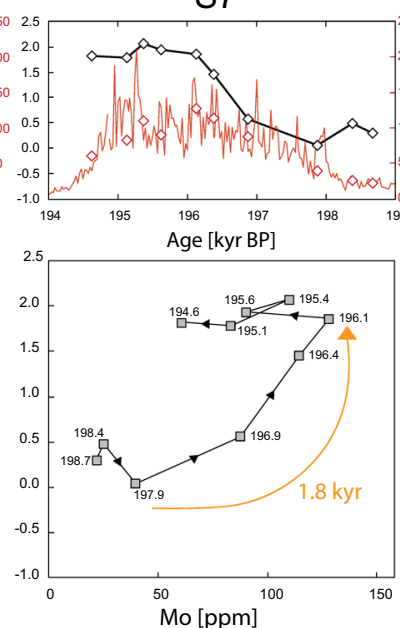

S4
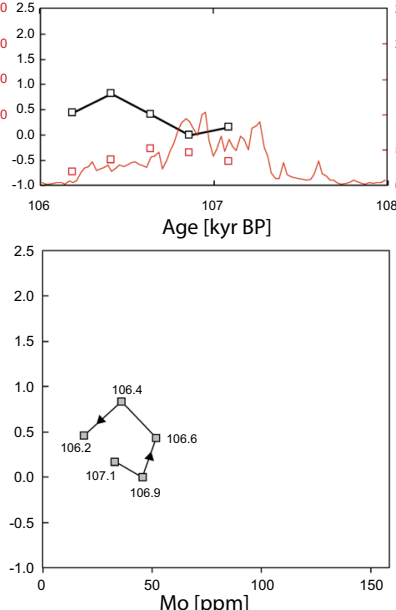

S5
S8
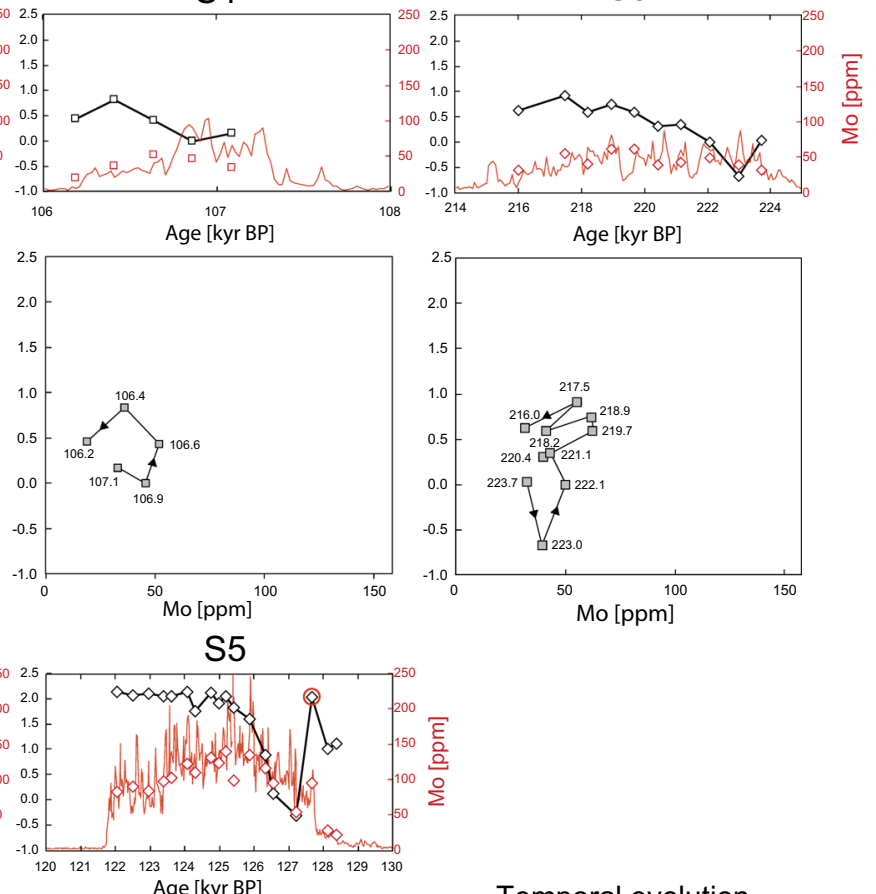

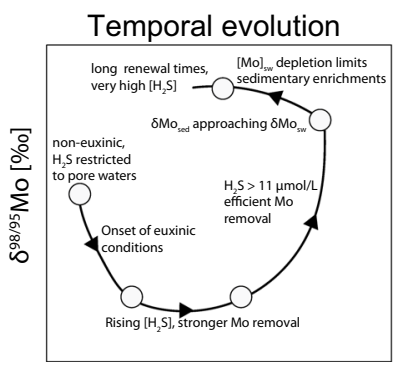

Mo [ppm]

Figure 4 Close up of data presented in Figure 2 for sapropel intervals, including cross plots with age labels. The orange arrows highlight similarities in temporal patterns between S5 and S7. The bottom right plot shows a schematic interpretation of temporal patterns. 
values seem to overestimate the fractionation between seawater and sediment for intermediate $\mathrm{H}_{2} \mathrm{~S}$ concentrations (Fig 3b; Dahl et al., 2010). Tuning the particle affinities to the available Black Sea data $(0.0001,0.1,5,25,25)$ improves the general fit, although the relative particle affinities remain poorly constrained. Therefore, here we only conservatively estimate $\left[\mathrm{H}_{2} \mathrm{~S}\right]$, by using Mo isotopes to constrain upper or lower limits of past $\left[\mathrm{H}_{2} \mathrm{~S}\right]$ that are valid for a range of different particle affinities (Fig. 3b, c).

Semi-Quantitative Reconstructions of Sapropel Euxinia. We distinguish between four different levels of euxinia, based on the calculations (Matthews et al., 2017) fitted to the Black Sea data (Fig. 3b) with additional constraints from the Mo concentration data (Fig. 3c). Low sedimentary $\delta^{98} \mathrm{Mo}$ values $(<-0.1 \%$ o) are taken as evidence for mildly euxinic conditions $\left(0<\left[\mathrm{H}_{2} \mathrm{~S}\right]<11 \mu \mathrm{mol} / \mathrm{L}\right)$. Conversely, for high $\delta^{98} \mathrm{Mo}$ values $\left(>1.8 \%\right.$ o), the $\mathrm{H}_{2} \mathrm{~S}$ to $\delta^{98} \mathrm{Mo}$ relationship flattens such that $\delta^{98} \mathrm{Mo}$ values can only roughly constrain past $\mathrm{H}_{2} \mathrm{~S}$ concentrations. These values $\left(\delta^{98} \mathrm{Mo}>1.8 \%\right.$ ) are accordingly taken to reflect dominantly highly sulfidic deep water conditions, with prevailing $\mathrm{H}_{2} \mathrm{~S}$ concentrations of at least $17 \mu \mathrm{mol} / \mathrm{L}$, but potentially much higher. $\delta^{98} \mathrm{Mo}$ values between -0.1 and $1.8 \%$ are less diagnostic by themselves, but can be interpreted considering the Mo concentrations of organic-rich sediments based on the limits for predominantly non-euxinic ( $<25 \mathrm{ppm})$, at least temporary euxinic (25-100 ppm), and mostly euxinic (>100 ppm) conditions (Scott and Lyons, 2012). Therefore, reasonably high $\delta^{98}$ Mo values ( $>1 \%$ ) with concentrations of $>25 \mathrm{ppm}$, and $\delta^{98} \mathrm{Mo}$ values of at least $-0.1 \%$ coupled to high (>100 ppm) Mo concentrations, are both considered to have been deposited in 'moderately euxinic' conditions, where conditions were dominantly sulfidic but with $\mathrm{H}_{2} \mathrm{~S}$ concentrations low enough to still allow fractionation between sediments and seawater.

Based on this framework, during deposition of sapropels S5 and S7 more sulfidic water column conditions $\left(\mathrm{H}_{2} \mathrm{~S}>\right.$ $17 \mu \mathrm{mol} / \mathrm{L})$ developed. This is in line with the study of Benkovitz et al. (2020), who infer euxinic conditions for sapropels S5 and S7 based on Fe isotope and speciation data. By contrast, moderately euxinic bottom water conditions developed during sapropel S6, whereas during sapropels S3, S4, S8, and S9 mildly euxinic conditions were reached $\left(0<\mathrm{H}_{2} \mathrm{~S}<11 \mu \mathrm{mol} / \mathrm{L}\right)$.

Temporal Patterns in Mo Concentrations and Isotopes. Similar temporal patterns in $[\mathrm{Mo}]$ and $\delta^{98} \mathrm{Mo}$ are observed for different sapropels, particularly for sapropels S5, S6, S7, and S8 (Fig. 4). This general pattern is similar to that defined by Black Sea surface sediments from different water depths (Fig. 3a), which implies that the sapropel S5-S8 data reflect a progressive increase in $\left[\mathrm{H}_{2} \mathrm{~S}\right]$ and evolution of the dissolved Mo pool. The relatively rapid changes in $\delta^{98} \mathrm{Mo}$ observed here ( $>2 \%$ o in $\sim 2 \mathrm{kyr}$ for S5) show that reconstructions of global redox changes on longer time scales from $\delta^{98} \mathrm{Mo}$ values in organic-rich sediments come with considerable uncertainty.

Mo Drawdown and Deep Water Renewal Times. The lower Mo concentrations and higher $\delta^{98} \mathrm{Mo}$ values found for the latter third of sapropels S5 and S7 is in line with progressive drawdown of dissolved Mo under highly sulfidic deep waters with long deep water renewal times, similar to conditions in the modern Black Sea (Nägler et al., 2011). Previous estimates of deep water residence times for sapropel S5 of $1030+820$ / -520 years approach that of the modern Black Sea (Andersen et al., 2018). Similarities in $\delta^{98} \mathrm{Mo}$ and Mo concentrations for sapropel S5 and S7 imply that deep water renewal times for S7 were comparable to that of S5. These results highlight that conditions remained strongly reducing throughout the sapropel, including towards the end of sapropel deposition, despite gradually lower
Mo concentrations. The other studied sapropels likely featured lower overall drawdown of dissolved Mo, implying shorter deep water residence times and/or rates of Mo drawdown.

\section{Conclusion}

High resolution Mo isotope and concentration data from different Mediterranean sapropels reveal consistent temporal patterns. With the use of models with a kinetic control on the different thiomolybdate species and by comparison to Black Sea data, these patterns can be interpreted to reflect increasingly more sulfidic conditions during the early stages of sapropel formation. The differences between sapropels seem to be driven primarily by changes in monsoon strength over North Africa, and associated run off of freshwater into the Mediterranean Sea. As such, these data highlight an under-appreciated ability of Mo isotope data to quantitatively constrain basin redox changes over several kyr. The highly variable Mo isotope values on relatively short $\left(10^{3}\right.$ years) time scales show that Mo isotopes should be used with great care when reconstructing global ocean redox conditions from black shales.

\section{Acknowledgements}

We thank the captain and crew of the R/V Pelagia cruise 64PE406, carried out under NESSC programme and financially supported by the Netherlands Ministry of OCW, grant number 024.002.001. We are thankful to B. van der Wagt, P. Laan, M. Klaver, and A. Dickson for analytical support. RH is supported through NWO grant ALW OP.2015.113 awarded to G.-J.R. Constructive comments by Tais Dahl and two anonymous reviewers have helped us to improve our manuscript.

Editor: Sophie Opfergelt

\section{Additional Information}

Supplementary Information accompanies this letter at https:// www.geochemicalperspectivesletters.org/article2108.

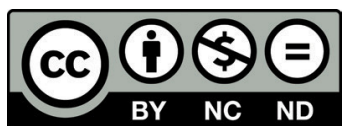

(C) 2021 The Authors. This work is distributed under the Creative Commons Attribution NonCommercial No-Derivatives 4.0 License, which permits unrestricted distribution provided the original author and source are credited. The material may not be adapted (remixed, transformed or built upon) or used for commercial purposes without written permission from the author. Additional information is available at https://www. geochemicalperspectivesletters.org/copyright-and-permissions.

Cite this letter as: Sweere, T., Hennekam, R., Vance, D., Reichart, G.-J. (2021) Molybdenum isotope constraints on the temporal development of sulfidic conditions during Mediterranean sapropel intervals. Geochem. Persp. Let. 17, 16-20.

\section{References}

Andersen, M.B, Matthews, A Vance, D Bar-Matthews, M. Archer, C DE SouzA, G. (2018) A 10-fold decline in the deep Eastern Mediterranean thermohaline overturning circulation during the last interglacial period. Earth and Planetary Science Letters 503, 58-67.

Andersen, M.B., Matthews, A., Bar-Matthews, M., Vance, D. (2020) Rapid onset of ocean anoxia shown by high $\mathrm{U}$ and low Mo isotope compositions of sapropel S1. Geochemical Perspectives Letters 15, 10-14. 
Azrieli-Tal, I., Matthews, A., Bar-Matthews, M., Almogi-Labin, A., Vance, D., Archer, C., TeUtsch, N. (2014) Evidence from molybdenum and iron isotopes and molybdenum-uranium covariation for sulphidic bottom water during Eastern Mediterranean sapropel S1 formation. Earth and Planetary Science Letters 393, 231-242.

Benkovitz, A., Matthews, A., Teutsch, N., Poulton, S.W., Bar-Matthews, M Almogi-Labin, A. (2020) Tracing water column euxinia in Eastern Mediterranean Sapropels S5 and S7. Chemical Geology, 119627.

Brüske, A., Weyer, S., Zhao, M.-Y., Planavsky, N., Wegwerth, A., Neubert, N., Dellwig, O., LAU, K., LyONS, T. (2020) Correlated molybdenum and uranium isotope signatures in modern anoxic sediments: Implications for their use as paleo-redox proxy. Geochimica et Cosmochimica Acta 270, 449-474.

Dahl, T.W., Anbar, A.D., Gordon, G.W., Rosing, M.T., Frei, R., Canfield, D.E (2010) The behavior of molybdenum and its isotopes across the chemocline and in the sediments of sulfidic Lake Cadagno, Switzerland. Geochimica et Cosmochimica Acta 74, 144-163.

Dahl, T.W Siggaard-Andersen, M.L, Schovsbo, N.H, Persson, D. O, Husted, S HougÅrd, I.W., DiCKSON, A.J., KJAR, K., NieLSEn, A.T. (2019) Brief oxygenation events in locally anoxic oceans during the Cambrian solves the animal breathing paradox. Scientific Reports 9, 1-9.

ERICKSON, B.E., Helz, G.R. (2000) Molybdenum (VI) speciation in sulfidic waters stability and lability of thiomolybdates. Geochimica et Cosmochimica Acta 64, 1149-1158.

Grant, K., Grimm, R., Mikolajewicz, U., Marino, G., Ziegler, M., Rohling, E. (2016) The timing of Mediterranean sapropel deposition relative to insolation, sea-level and African monsoon changes. Quaternary Science Reviews 140, $125-141$.

Hennekam, R., van der Bolt, B., van Nes, E.H., de Lange, G.J., Schefrer, M. REICHART, G.-J. (2020) Early-warning sionals for marine anoxic events. Geophysical Research Letters 47, e2020GL089183.

Kendall, B., DahL, T., AnBar, A.D. (2017) The stable isotope geochemistry of molybdenum. Reviews in Mineralogy and Geochemistry 82, 683-732.

Kerl, C.F., Lohmayer, R., Bura-Nakić, E., Vance, D., Planer-Friedrich, B. (2017) Experimental confirmation of isotope fractionation in thiomolybdates using ion chromatographic separation and detection by multicollector ICPMS. Analytical Chemistry 89, 3123-3129.

Matthews, A., Azrieli-Tal, I., Benkovitz, A., Bar-Matthews, M., Vance, D Poulton, S.W., Teutsch, N., Almogi-Labin, A., Archer, C. (2017) Anoxic development of sapropel S1 in the Nile Fan inferred from redox sensitive proxies, Fe speciation, Fe and Mo isotopes. Chemical Geology 475, 24-39.

NÄgler, T., Neubert, N., Böttcher, M., Dellwig, O., Schnetger, B. (2011) Molybdenum isotope fractionation in pelagic euxinia: evidence from the modern Black and Baltic Seas. Chemical Geology 289, 1-11.

Nakagawa, Y., Takano, S., Firdaus, M.L., Norisuye, K., Hirata, T., Vance, D., SoHRIN, Y. (2012) The molybdenum isotopic composition of the modern ocean. Geochemical Journal 46, 131-141.

NeUbert, N., NäGler, T.F., BÖtTCHER, M.E. (2008) Sulfidity controls molybdenum isotope fractionation into euxinic sediments: Evidence from the modern Black Sea. Geology 36, 775-778.

ReItZ, A., Wille, M., Nägler, T.F., De Lange, G.J. (2007) Atypical Mo isotope signatures in eastern Mediterranean sediments. Chemical Geology 245, 1-8.

Rohling, E., MARINO, G., Grant, K. (2015) Mediterranean climate and oceanography, and the periodic development of anoxic events (sapropels). EarthScience Reviews 143, 62-97.

ScotT, C., Lyons, T.W. (2012) Contrasting molybdenum cycling and isotopic properties in euxinic versus non-euxinic sediments and sedimentary rocks: Refining the paleoproxies. Chemical Geology 324, 19-27.

TossebL, J. (2005) Calculating the partitioning of the isotopes of Mo between oxidic and sulfidic species in aqueous solution. Geochimica et Cosmochimica Acto 69, 2981-2993

Ziegler, M., Tuenter, E., Lourens, L.J. (2010) The precession phase of the boreal summer monsoon as viewed from the eastern Mediterranean (ODP Site 968). Quaternary Science Reviews 29, 1481-1490. 